\title{
RELIGIÃO, SAÚDE E CORPORALIDADES: TENDÊNCIAS E PERSPECTIVAS CONTEMPORÂNEAS
}

\section{ISABEL SANTANA DE ROSE, RODRIGO TONIOL E SILVIA MARTINS}

Religião, saúde e corporalidades constitui o eixo organizador dos textos reunidos neste dossiê. Reconhecemos que trata-se de um tema tão amplo quanto clássico nos debates das ciências sociais. Sua amplitude carrega uma característica ambígua. Por um lado, resulta no acúmulo de dados empíricos sobre o tópico, que expandem nosso repertório de entendimento sobre as variadas formas de conjunção dessas dimensões. Por outro, ao refletir a respeito dessas articulações a antropologia tem avançado em críticas metadisciplinares, que colocam à prova sua própria forma de produzir enquadramentos sobre o que seja religião, saúde e corporalidade. Este dossiê procura preservar essa dupla característica, já que com ele pretendemos tanto apresentar fenômenos empíricos que reforçam a vitalidade das articulações entre essas dimensões, quanto refletir sobre a pertinência ou não do uso desses termos como categorias de análise. Essa proposta implica em estarmos atentos(as) às discussões presentes na teoria antropológica contemporânea, que tem incidido criticamente sobre dualismos como mente/corpo, mundo/pessoa e sujeito/objeto. Neste volume, essas reflexões parecem ecoar alguns debates mais amplos, brevemente sintetizados a seguir.

No que diz respeito aos questionamentos das dicotomias cartesianas como corpo/mente, objeto/sujeito, sem dúvida uma referência central no âmbito da produção antropológica é o trabalho de Thomas Csordas (2008). Empregando conceitos como embodiment ou corporeidade e modos somáticos de atenção, ele propõe estabelecer um diálogo com a fenomenologia. Csordas traz para o primeiro plano da análise as relações entre corpo e processos de percepção, buscando compreender a experiência cultural como corporificada. Já entre os autores e autoras brasileiros que vêm dialogando com essa abordagem, ressaltamos o trabalho de Miriam Rabelo que recorre à fenomenologia para analisar as relações entre religião e cura, a produção do sentido e a transformação da experiência (ver, entre outros, RABELO, 2007, 2010 e 2014). Com base em pesquisas de campo conduzidas em diferentes contextos etnográficos, ela sugere que a cura nos tratamentos religiosos deve ser vista como uma realidade processual que envolve intersubjetividade, negociações constantes e engajamento ativo dos diversos atores envolvidos (RABELO, 2010).

Outra discussão que atravessa vários dos textos presentes no dossiê diz respeito às relações entre as diversas práticas e grupos abordados com o movimento eclético e heterogêneo denominado como "Nova Era", "nova consciência religiosa" ou "circuito neo- 
esotérico" (MAGNANI, 1999), entre outros termos. Este fenômeno encontra-se ligado à emergência de um campo de intersecção entre novas formas de espiritualidade e religiosidade, práticas terapêuticas alternativas e a vivência de experiências ecléticas pelas classes médias urbanas; ou ainda, a emergência de uma "nova cultura espiritual" (ver, entre outros, MALUF, 2003, 2005; TAVARES, 2012). De acordo com Sônia Maluf (2003), as especificidades desse movimento no caso brasileiro incluem a confluência entre o religioso e o terapêutico; o ecletismo religioso; a informalidade das práticas terapêuticas; a existência de um pluralismo terapêutico; e a intensa mobilidade e circulação das pessoas entre diferentes experiências terapêuticas e rituais. Contrapondo-se a abordagens que sugerem que esse movimento seria apenas uma bricolage de concepções, práticas, objetos de consumo e rituais sem qualquer princípio ordenador, ou ainda um reflexo do individualismo contemporâneo, Maluf (2005) considera que a adoção do trabalho terapêutico e do desenvolvimento espiritual está ligada à constituição de projetos e estilos de vida mais amplos no contexto das metrópoles.

Os autores e autoras presentes no dossiê refletem também sobre questões metodológicas envolvidas nas pesquisas com religião, espiritualidade e temas afins, em diferentes contextos etnográficos. Essas reflexões englobam o próprio processo da escrita etnográfica, que muitas vezes precisa lidar com atores não-humanos, mundos invisíveis, segredos e tabus, entre outros aspectos que desafiam a racionalidade ocidental. Somado a isso, possivelmente os fenômenos situados neste campo trazem maior possibilidade de afetar de maneiras decisivas os pesquisadores que se defrontam com eles, levantando questionamentos sobre seus projetos de conhecimento (FAVRET-SAADA, 2005). Como vemos em alguns dos textos a seguir, esse movimento pode gerar deslocamentos epistemológicos, implicando em reflexões sobre a pesquisa etnográfica e o fazer científico de modo mais amplo.

Finalmente, é importante chamar atenção para a relevância do campo ayahuasqueiro dentro das discussões contemporâneas sobre religião, saúde e corporalidade, sendo que três dos sete artigos reunidos no dossiê tem como base etnografias realizadas entre diferentes grupos e movimentos fazem parte deste circuito: um centro comunitário e terapêutico eclético em Buenos Aires; um centro terapêutico na Amazônia peruana voltado para o tratamento de dependências; e dois grupos ligados ao Santo Daime localizados em Minas Gerais. Por um lado, a presença de um número considerável de artigos que abordam o campo ayahuasqueiro neste volume pode estar relacionada às trajetórias de pesquisa de duas de suas organizadoras, Isabel de Rose e Sílvia Martins, que desenvolve abordagens 
dentro do campo da antropologia audiovisual e sensorial. ${ }^{1}$ Por outro lado, também é possível sugerir que isso constitui um indicativo da relevância que os diversos usos da ayahuasca vêm adquirindo nas redes nacionais e internacionais ligadas ao movimento da Nova Era e aos neoxamanismos, principalmente ao longo das últimas duas décadas, bem como para a multiplicação de pesquisas sobre essas redes contemporâneas (ver, entre outros, LABATE; CAVNAR, 2018).

O trabalho de Ana Elisa F. Bersani que abre o dossiê enfoca a experiência de negros de origem haitiana em São Paulo, problematizando dinâmicas sociais que envolvem a gestão da saúde, da doença e do sofrimento. O texto é baseado em pesquisa de campo realizada junto à diáspora haitiana e às organizações que integram a Rede de Cuidados aos Imigrantes e Refugiados na metrópole paulistana, trazendo também diálogos com a investigação anterior da autora conduzida no Haiti. Bersani enfatiza a importância de levar em conta o universo mágico-religioso para compreender os processos dos haitianos vividos em solo brasileiro. O texto é atravessado pela descrição da história de Joseph, imigrante que vivia em situação de rua e que morreu, segundo a interpretação de sua família, de maladi fetich ou "doença de feitiço". Partindo dessa trajetória, a autora chama atenção para a recorrência das histórias que enlaçam infortúnios ao universo místico da magia e do feitiço na pesquisa com os haitianos, tanto no Brasil como no Haiti. Ela ressalta também a estreita relação entre a experiência migratória e o adoecimento. Para Bersani, ideias como precariedade, crise, desconforto e sofrimento se associam e são associadas à experiência migratória, constituindo o que ela chama de fenômeno do "mal-estar". A autora situa o "mal-estar" enquanto um problema etnográfico, sugerindo tomar essa ideia como um "dispositivo que permite expandir o olhar, considerando as distintas formas de vivenciar e interpretar o sofrimento". Nesse sentido, Bersani busca evitar uma substancialização ou definição estanque desta categoria, que procura elaborar de modo amplo e fluido, e em estreito diálogo com as narrativas dos seus interlocutores de pesquisa.

Abordando um contexto etnográfico completamente diferente, o artigo de Gabriela Cunha dos Santos é baseado em uma etnografia junto a terapeutas da Análise Bioenergética. A autora realizou trabalho de campo em diferentes capitais brasileiras acompanhando atividades de aprendizagem e formação, bem como eventos acadêmicos e institucionais ligados a essa prática. O texto se insere em um debate mais amplo sobre as terapias corporais, parte das quais passaram a ser absorvidas pela Política Nacional de Práticas Integrativas e Complementares (PNPIC) (ver também TONIOL, 2018). O trabalho aponta para

\footnotetext{
${ }^{1}$ Martins vem produzindo vários filmes etnográficos recentes sobre o tema. Ver, entre outros, The making of "daime" (38'03", 2020, disponível em https://vimeo.com/396206362); Baptiste é um yogui ayahuasqueiro (16'07", 2020, disponível em https://vimeo.com/394680196); Kitxtí Huni-Kuin no Estrela Universal (26'20", 2020, disponível em https://youtube/ICLFIv--2Tk).
} 
um dos eixos transversais centrais no dossiê mencionado acima: a discussão sobre o movimento da Nova Era; nesse caso, especificamente, a relação deste fenômeno com a difusão e expansão das terapias corporais.

Já o texto de Hozana Passos apresenta um estudo no campo da antropologia musical, em diálogo com a etnomusiciologia e também nas interfaces com os temas de saúde e espiritualidade. A autora investiga os sentidos do fazer musical no contexto dos tratamentos espirituais oferecidos pela Sociedade Espírita Everilda Batista, ou Casa de Everilda, localizada em Contagem, MG, partindo da experiência dos cuidadores/trabalhadores e da vivência das pessoas cuidadas/consulentes. Nesse contexto, Passos aponta que a música pode ser considerada como um elemento terapêutico e sugere pensar o fazer musical como uma prática de "cuidado de si", mediada pelos sujeitos dos mundos tanto visível quanto invisível. A autora enfoca os conceitos de ser humano, corpo, saúde, música e espiritualidade que emergiram do campo.

Abrindo os artigos sobre o campo ayahuasqueiro, a proposta do texto de Maria Soledad del Rio é de mapear as noções de "bem-estar" presentes em um centro comunitário e terapêutico (CCT) na cidade de Buenos Aires, voltado para oferecer cerimônias de ayahuasca e tabaco, entre outras atividades. Este centro é conduzido por um casal de psicólogos e se apresenta como um "espaço eclético", combinando distintas técnicas da psicologia com práticas do curandeirismo amazônico. Somado a isto, os participantes do CCT constituem um grupo bastante heterogêneo no que diz respeito a questões como gênero, idade, formação e trabalho. Del Rio enfoca especialmente a categoria nativa de sentir e argumenta que nesse contexto os significados da noção de bem-estar envolvem um tipo particular de estética, ligada à experiência sensorial do mundo e de si mesmo. Deste modo, a categoria de sentir está associada a uma "estética do bem-estar" que deve ser compreendida como resultado das relações entre humanos e não-humanos, incluindo as plantas de tabaco e ayahuasca. Outra ideia importante presente no texto de del Rio é que as experiências com ayahuasca no âmbito do CCT apontam para uma ressignificação do que poderíamos designar como "mal-estar", isto é, os efeitos fisiológicos comuns da bebida, que frequentemente incluem náuseas e vômito, e que neste contexto constituem uma parte central do processo de cura. A autora argumenta, portanto, que o sentir engloba dois aspectos que a princípio poderiam parecer contraditórios, mas que a pesquisa de campo aponta como sendo pertencentes a uma mesma lógica particular: o "mal-estar" e o "bem-estar". Deste modo, estes aspectos aparecem como parte de uma mesma experiência; se sobrepõem e se complementam.

Partindo de uma revisão crítica das experiências etnográficas das autoras no Brasil e no Peru, o texto de Ana Gretel E. Böschmeier e Camila de Pieri Benedito traz uma contribuição importante ao abordar as relações entre discussões metodológicas e 
epistemológicas e questões de gênero, especificamente dentro das pesquisas conduzidas nos circuitos ayahuasqueiros. O texto enfoca as dificuldades e riscos que as pesquisadoras podem encontrar em campo nesses contextos, bem como as possibilidades e potencialidades das investigações realizadas por mulheres. A premissa do trabalho é que existem estruturas de gênero pouco discutidas, tanto nas investigações sobre o tema quanto nas situações cotidianas dos circuitos ayahuasqueiros, constituídos por contextos "marcados por lideranças tradicionais, políticas e espirituais reconhecidamente masculinas". Entretanto, apesar dessa presença majoritária de líderes homens neste campo e do apagamento das sexualidades não normativas, as autoras apontam que pouco é falado sobre gênero e sexualidades na bibliografia especializada.

E. Böschmeier constrói uma discussão a partir da experiência de campo em um centro ayahuasqueiro localizado na Amazônia peruana internacionalmente conhecido e que constitui um modelo de tratamento de dependências na América Latina. De acordo com a autora, as terapias que têm destaque neste espaço são associadas ao vegetalismo peruano: dietas, purgas e cerimônias com ayahuasca. Ela argumenta que esse centro, que se projeta como exemplo de tratamento intercultural por meio do uso de terapias com plantas, está enraizado em uma "estrutura formada por homens e para homens". A autora traz, portanto, um depoimento sobre um campo caracterizado por um silêncio generalizado a respeito de questões de gênero e sexualidade, bem como pela invisibilização e mesmo rejeição do lugar de pesquisadoras mulheres. Infelizmente, como ela aponta, as formas de discriminação baseadas no sexismo não são exclusivas desse espaço, mas se estendem para a maioria das práticas ligadas ao turismo ayahuasqueiro presentes na Amazônia peruana. Já a narrativa de Benedito é baseada em uma pesquisa de campo conduzida em uma comunidade do Santo Daime localizada no sul de Minas Gerais caracterizada, segundo a autora, por uma rígida separação ritual, espacial e de trabalho entre homens e mulheres, e por uma classificação binária e estática dos gêneros. Ela enfoca a elaboração dos conceitos de masculino e de feminino nessa comunidade e chama atenção para o fato de ser mulher como um aspecto muito marcante na experiência de pesquisa, fazendo com que os significados do masculino e do feminino extravasassem a posição de objeto de pesquisa e definissem também sua própria posição em campo.

Partindo dessas reflexões baseadas em dois contextos distintos, mas que trazem aspectos transversais comuns, especialmente no que diz respeito a questões de gênero e as implicações de ser mulher em campo, as autoras elaboram algumas propostas e recomendações para as etnógrafas que se aventuram no circuito ayahuasqueiro. Elas enfocam as potencialidades das pesquisas realizadas por mulheres e por pessoas LGBTQI+ e chamam atenção para a importância de abordar questões como desigualdades de gênero, discriminação sexual e violações de direitos humanos em contextos de pesquisa etnográfica. 
Embora Echazú B. e Benedito enfatizem as discussões sobre o circuito ayahuasqueiros e as recomendações sejam elaboradas pensando as especificidades desses cenários, sem dúvida suas reflexões podem ser estendidas para outros contextos etnográficos nos quais as questões de gênero também impactam nas pesquisas, e especialmente nas investigações conduzidas por mulheres e pessoas LGBTQI+. Não se trata aqui de questionar a presença das assimetrias e mesmo violências de gênero no circuito ayahuasqueiro. Pelo contrário, as autoras trazem uma contribuição fundamental ao chamar atenção para esses aspectos, muitas vezes invisibilizados e naturalizados, tanto nas práticas cotidianas dos grupos quanto nas pesquisas sobre o tema. Entretanto, essas questões certamente se encontram presentes em outros contextos ligados ao campo religioso brasileiro e global, o que só reforça a importância da discussão. ${ }^{2}$

Já o artigo de Francisco Savoi Araújo enfoca o debate sobre a cura no Santo Daime com base em uma pesquisa de campo conduzida no Centro Livre Nossa Senhora da Saúde (CLNSS), localizado em Lagoa Santa, MG. Partindo da própria experiência pessoal, da observação participante e da realização de entrevistas com membros deste centro, ele propõe enfocar as concepções de corpo, saúde e doença para os daimistas. Dialogando com algumas referências clássicas da área da antropologia da saúde, Araújo chama atenção para as interseções entre espiritualidade/religiosidade e saúde, bem como a imbricação entre curas físicas, psíquicas e/ou espirituais. Estas intersecções e imbricações certamente não são exclusivas desse campo, e se encontram presentes também em outros contextos (ver, entre outros, MALUF, 2005; TAVARES, 2012), como indicam diversos dos artigos presentes no dossiê. A principal contribuição do texto de Araújo para os debates mais específicos sobre a cura no Santo Daime está na ênfase na autonomia e na participação do paciente em seu processo de cura, bem como o destaque para a responsabilidade individual pela própria transformação. Nesse sentido, o daime (bebida) é apresentado como um "veículo" ou "facilitador" do processo de cura, sendo que este processo encontra-se estreitamente associado a ideias como autoconhecimento, transformação e busca espiritual.

Finalmente, o texto de Leomar da Silva Lima e Nivaldo Aureliano Léo Neto traz uma contribuição interdisciplinar, pois os dois autores vêm da área das ciências biológicas. Assim, ao fazerem um mapeamento das práticas de benzeção presentes no povoado de Lages localizado no município de Porto de Pedras, litoral norte de Alagoas - eles buscam dialogar com a etnobotânica, realizando um levantamento preliminar das plantas utilizadas pelas

\footnotetext{
${ }^{2}$ No Brasil essas questões obtiveram visibilidade nos debates públicos no ano de 2018 , em que o campo religioso foi marcado por denúncias relativas a abuso sexual em diferentes contextos, incluindo episódios dentro e fora do campo ayahasqueiro. Entre esses episódios, possivelmente o que obteve maior destaque na mídia foi o caso do médium João de Deus, preso devido a uma série de denúncias de abuso e assédio sexual.
} 
benzedeiras e curadores nesse povoado. A metodologia empregada pode ser considerada interdisciplinar, pois os autores conduziram pesquisa de campo e realizaram observação participante. Entretanto, a investigação está centrada principalmente na aplicação de questionários semi-estruturados, tanto entre as benzedeiras e curandeiros quanto entre a população local. Eles apontam para possíveis conexões com outras pesquisas sobre benzedeiras e curandeiros, bem como com levantamentos sobre os usos de plantas nas práticas de medicina popular em diferentes regiões no Nordeste. Com base nos questionários aplicados e nessas conexões, os autores ressaltam a diversidade presente nos curadores e benzedeiras abordados na pesquisa no que diz respeito a aspectos como gênero, etnicidade, identidade social, idade, filiação religiosa e outros. Eles argumentam ainda que, mesmo havendo semelhanças nas formas de benzer, há também muitas particularidades e diferenças.

Para concluir essa apresentação, gostaríamos de retomar algumas das tendências e perspectivas transversais presentes nas abordagens contemporâneas sobre religião, saúde e corporalidades mencionadas no início deste texto. Além de chamar atenção para a visibilidade desse fenômeno no contexto atual, os trabalhos sobre o circuito ayahuasqueiro apontam para uma possível mudança nas análises sobre este tema. Num primeiro momento as investigações sobre os usos da ayahuasca, e especialmente sobre as religiões ayahuasqueiras brasileiras, mantiveram um caráter fortemente endogâmico, dialogando pouco com questões presentes na teoria antropológica ou no campo de estudos sobre religião de modo mais amplo. Entretanto, na produção mais recente, principalmente ao longo dos últimos dez anos, essa tendência vem mudando, como indicam alguns dos textos presentes no dossiê, que relacionam as investigações sobre os usos da ayahuasca em diferentes contextos etnográficos com discussões a respeito de gênero, direitos humanos, estética, agência não humana, e questões metodológicas e epistemológicas centrais para as ciências humanas e sociais.

No que diz respeito ao fenômeno da "Nova Era", enquanto alguns trabalhos presentes neste volume tomam a associação dos grupos, práticas e movimentos investigados com este movimento como dada, outros problematizam esta noção, sugerindo que ela emerge como uma categoria das próprias ciências sociais e apontando para outros percursos possíveis. Nesse sentido, Santos argumenta que a "Nova Era" consiste na via de análise mais frequentemente acionada para compreender a disseminação das terapias corporais, incluindo a Análise Bioenergética. A autora indica que o pluralismo terapêutico constitui um fenômeno complexo que ultrapassa as fronteiras dos estudos sobre religião e problematiza a tendência de abordar as terapias corporais a partir do recorte da Nova Era, ressaltando a importância de estabelecer relações com os estudos sobre a cultura psi para desenvolver uma compreensão mais ampla desse fenômeno. Já Araújo propõe pensar o Santo Daime 
enquanto uma "religião da Nova Era", que ressalta o indivíduo ou self enquanto agente da própria cura, independente da influência de agentes externos. Ele sugere, portanto, que o Santo Daime seja visto como uma "terapia religiosa" inserida num contexto mais amplo de medicinas alternativas e do movimento da Nova Era. Del Rio, por sua vez, chama atenção para a recorrência das associações entre as "espiritualidades contemporâneas" com noções de bem-estar e saúde ao longo das últimas décadas, indicando que estas não estão presentes apenas nas reflexões acadêmicas sobre o tema, mas muitas vezes são propostas pelos próprios membros dos grupos pesquisados. Como Santos, esta autora também problematiza a ênfase que as ciências sociais tendem a colocar na categoria de Nova Era e evita referir-se ao centro pesquisado como sendo uma "religiosidade contemporânea", uma "terapia alternativa" ou uma "prática da Nova Era". No caso de del Rio, esta evitação é resultado de uma "pausa analítica", pois ela considera que não se deve usar essas categorias sem considerável revisão e reflexão prévias.

Alguns dos textos reunidos no dossiê indicam que os questionamentos de divisões e categorias analíticas clássicas como mente/sujeito/cultura e corpo/objeto/biologia são elaborados tanto no âmbito das práticas, grupos e movimentos pesquisados quanto nos estudos acadêmicos. Este é o caso do trabalho de Santos sobre a Análise Bioenergética, cujos praticantes, segundo ela, enfocam a continuidade entre corporalidade e subjetividade. Já del Rio aciona os conceitos de corporeidade e modos somáticos de atenção propostos por Csordas para abordar a "estética do bem-estar" desenvolvida pelos participantes do CCT. Ela aponta que toma estes conceitos em dois sentidos: numa primeira direção, eles são vistos como um paradigma e orientação metodológica, onde o trabalho de campo é realizado prestando atenção a e com o corpo, incluindo o corpo da investigadora. Numa segunda direção complementar, eles são empregados como conceitos teóricos, visando dialogar com as categorias nativas. Nesse sentido, ela indica que o sentir não se concentra numa parte específica do corpo; trata-se mais da experiência do "corpo vivido", que não é somente o corpo biológico, mas o "corpo do sentir". Somado a isto, o sentir se estende e se expande até outros corpos, envolvendo uma "educação da atenção" (INGOLD, 2014). De acordo com del Rio, o sentir educa o corpo na direção dos modos somáticos de atenção, que são culturalmente constituídos. Bersani, por sua vez, opta por outra via. Propondo conjugar abordagens da antropologia da saúde e da religião, ela busca explorar a potencialidade do trabalho etnográfico para refletir sobre a experiência migratória. A autora parte de uma "perspectiva que extrapole as dicotomias entre ciência e religião, medicina e cultura ou corpo e espíritos". Bersani sugere ainda deslocar "discursos que polarizam superficialmente os atores, os saberes e as práticas" e busca aproximar-se da experiência vivida.

Finalmente, as reflexões metodológicas e epistemológicas têm destaque nos trabalhos presentes neste volume, apontando para a importância de refletir sobre as 
especificidades nas pesquisas que envolvem religião e/ou espiritualidade. Passos chama atenção para os desafios dos encontros etnográficos envolvidos na sua pesquisa a respeito do fazer musical e que incluem a própria escrita. Ela também comenta sobre os deslocamentos epistemológicos provocados pelo processo de ser afetada em campo. A forma adotada pela autora para enfrentar esses desafios foi a ênfase na multiculturalidade e o diálogo com a diversidade. De maneira semelhante, Bersani enfatiza a importância da compreensão das narrativas êmicas, o que está ligado à tentativa de "levar a sério" o que os haitianos dizem. Desta forma, ela propõe abordar a "cultura" ou a "diferença cultural" não como um problema a ser ultrapassado, visando uma síntese homogeneizadora, mas como um elemento-chave da experiência. Esta autora também ressalta a importância da pesquisa etnográfica para pensar o tema da saúde e suas possíveis articulações, como a experiência da migração. Já Echazú B. e Benedito propõem realizar uma "reflexão epistemológica, metodológica e pedagógica no interior do campo de estudos sobre práticas e espaços vinculados à ayahuasca na América Latina". Para estas autoras, abordar experiências frequentemente negligenciadas em campo constitui uma forma não apenas de compreender melhor esses mundos, mas também de buscar transformá-los.

Os trabalhos reunidos nesse dossiê indicam como as investigações sobre religião, saúde e corporalidades dialogam com aspectos centrais do mundo contemporâneo e da teoria antropológica, incluindo diáspora e experiência migratória; assimetrias e violências de gênero; estética, bem estar e cuidado de si; práticas de medicina popular, terapias corporais e outras opções terapêuticas que apontam para o questionamento da hegemonia biomédica, entre outras questões. Somado a isto, enquanto observamos no Brasil e no mundo a escalada de governos autoritários de extrema direita, bem como um aumento significativo de episódios de racismo, intolerância religiosa, preconceito e discriminação, essas etnografias sensiveis expandem o olhar, chamando atenção para a multiplicidade de mundos, atores, sujeitos e narrativas alternativas. Nesse sentido, ao mesmo tempo que as reflexões dos autores e autoras presentes nesse volume apontam para algumas tendências e perspectivas teóricas possíveis nas análises sobre essas questões, esses textos também ressaltam a relevância e a potência da pesquisa etnográfica e qualitativa, que não pode deixar de ser pensada como uma espécie de ação política.

\section{REFERÊNCIAS}

FAVRET-SAADA, Jeanne. Ser afetado. Cadernos de cam p 0, v.13, n. 1, p. 155-161, 2005.

CSORDAS, Thomas. Corpo, significado, cura. Porto Alegre, Editora da UFRGS, 2008. 
INGOLD, Tim. That's enough about ethnography! Hau: Journal of ethnographic theory , v.4, n. 1, p. 383-395, 2014.

LABATE, Beatriz; CAYNAR, Clancy. The expanding world ayahuasca diáspora. Apropriation, integretion and legislation. Nova Iorque/Londres: Routledge, 2018.

MAGNANI, José Guilherme C. Mystica urbe. Um estudo antropológico sobre o circuito neo-esotérico na metrópole. São Paulo, Studio Nobel, 1999.

MALUF, Sônia W. Os filhos de Aquário no país dos terreiros: novas vivências espirituais no sul do Brasil. Ciencias Sociales y Religión, v. 5, n. 5, p. 153-171, 2003.

MALUF, Sônia W. Mitos coletivos, narrativas pessoais: cura ritual, trabalho terapêutico e emergência do sujeito nas culturas da "Nova Era". Mana, v. 11, n. 2, p. 499-528, 2005.

RABELO, Miriam Cristina. Religião e a Transformação da Experiência: notas sobre o estudo das práticas terapêuticas nos espaços religiosos. Ilha, n. 7, p. 125-145, 2007.

RABELO, Miriam Cristina 2010. A construção do sentido nos tratamentos religiosos. RECIIS. Revista eletrônica de comunicação, informação \& inovação em saúde, n.4, p. 3-11, 2010.

RABELO, Miriam Cristina. Enredos, feituras e cuidados. Dimensões da vida e da convivência no Candomblé. Salvador: EDUFBA, 2014.

TAVARES, Fátima. Alquimistas da cura: a rede terapêutica alternativa em contextos urbanos. Salvador: UFBA, 2012.

TONIOL, Rodrigo. Do espírito na saúde: oferta e uso de terapias alternativas/complementares nos serviços de saúde pública no Brasil. São Paulo: LiberArs, 2018. 